\title{
Vitamin $\mathbf{K}$-dependent protein $\mathbf{S}$ is similar to rat androgen-binding protein
}

\author{
Michael E. BAKER, ${ }^{*}$ Frank S. FRENCH $\dagger$ and David R. JOSEPH $\dagger$ \\ *Department of Medicine, M-023, University of California, San Diego, La Jolla, CA 92093, and †Department of Pediatrics, \\ University of North Carolina School of Medicine, Chapel Hill, NC 257514, U.S.A.
}

\begin{abstract}
Vitamin $\mathrm{K}$-dependent protein $\mathrm{S}$ belongs to the family of clotting factors (e.g. Factors IX and $\mathrm{X}$, and protein C). Unlike the other clotting factors, the $C$-terminal half (residues 250-634) of protein $S$ is not a serine proteinase. In fact, the function of residues $250-634$ of protein $S$ is unknown. By using computer programs designed to detect evolutionary relationships between proteins, we find that this part of protein $\mathrm{S}$ is similar to rat androgen-binding protein, a protein produced and secreted by testicular Sertoli cells. The homology between protein $\mathbf{S}$ and androgen-binding protein suggests new approaches for elucidating their functions.
\end{abstract}

\section{INTRODUCTION}

Protein $\mathrm{S}$ is a vitamin $\mathrm{K}$-dependent protein (DiScipio \& Davie, 1979) that has at least two physiological properties: (1) it is a cofactor with activated protein $\mathrm{C}$ in the regulation of blood clotting (Walker, 1981; Gardiner et al., 1984), and (2) it forms a non-covalent complex with the regulatory complement-protein-C4b-binding protein (Dahlbäck \& Stenflo, 1981; Dahlbäck, 1983). People with a hereditary protein $S$ deficiency are predisposed towards venous thrombosis (Schwarz et al., 1984; Comp et al., 1984). Despite the physiological importance of protein S, most of the details of its biological actions remain unknown. The determination of the primary amino acid sequence of protein $S$ was an important step towards unravelling the functions of this protein (Dahlbäck et al., 1986). The amino acid sequence revealed that the first approx. 250 residues from the $\mathrm{N}$-terminus of protein $\mathrm{S}$ are similar in structure to other vitamin K-dependent clotting factors. First there is a 44-residue domain which contains the $\gamma$-carboxyglutamic acid (Gla) residues. After this sequence is a 30-residue segment that is sensitive to thrombin, which is followed by a 160-residue segment that is similar to epidermal growth factor (Dahlbäck et al., 1986). The function of the remainder of the $C$-terminal sequence, residues $250-634$, which constitutes about $60 \%$ of protein $S$, is unknown. It is clear, however, that it does not have any similarity to serine proteinases, which is what might be expected by analogy to other clotting factors (Patthy, 1985). Serendipitously, as part of a project to search for similarities between steroid-hormone-binding proteins and serine proteinases, one of us (Baker, 1985) discovered a strong similarity between the amino acid sequences of this $C$-terminal domain of protein $S$ and that of rat androgen-binding protein (ABP). ABP is produced and secreted by testicular Sertoli cells and binds androgens and oestrogens with high affinity (French \& Ritzen, 1973; Hansson et al., 1973, 1976). The homology between ABP and protein $S$ suggests an interesting genealogy for protein $\mathrm{S}$ and the possibility for novel ways for regulating the clotting process.

\section{RESULTS AND DISCUSSION}

The comparisons of the sequences of protein $S$ (Dahlbäck et al., 1986) and ABP (Joseph et al., 1986) were done by using the RELATE and ALIGN computer programs, which were developed at the National Biomedical Research Foundation to detect evolutionary relationships between proteins (Barker \& Dayhoff, 1982; Dayhoff $e t$ al., 1983). A RELATE analysis of protein S with ABP using a segment length of 30 gave a comparison score that was 17.4 S.D. higher than that of 100 comparisons of randomized sequences of these proteins. The probability of getting this score by chance is less than $10^{-50}$. Fig. 1 is a graphical representation (Maizel \& Lenk, 1981; Staden, 1982) of the similarity between of residues 250-634 of protein $S$ and ABP. Similar segments extend throughout $\mathrm{ABP}$ and the $C$-terminus part of protein S, and there is an off-diagonal similarity between residues $221-254$ of ABP and residues 282-315 of protein $S$. The segments along the diagonal of Fig. 1 are presented in more detail in Fig. 2. An ALIGN analysis of segments $A, C$, and $D$ of protein $S$ and $A B P$ gave comparison scores that were 13.5, 10.5 and 6.75 S.D. higher respectively than that obtained with 2500 comparisons of randomized sequences of these proteins. The probability of getting these scores by chance is less than $10^{-40}, 10^{-25}$ and $10^{-11}$ respectively. An ALIGN analysis of residues 221-254 of ABP with residues 282-315 of protein S yields a score of 7.4 S.D. units. Recently, the amino acid sequence of human sex-steroid-binding protein (SBP) was determined (Walsh et al., 1986), and it was found to be $70 \%$ homologous with that of rat ABP (Joseph et al., 1986; Walsh et al., 1986). The RELATE comparison of SBP with protein S yields a comparison score 16.7 S.D. higher than that of 100 comparisons of randomized sequences of these proteins, and the distribution of similar segments between these proteins and their ALIGN comparison scores are like that of ABP and protein $S$.

The vitamin K-dependent clotting factors are an example of the shuffling of exons or modules with different functions to assemble proteins to meet a variety 


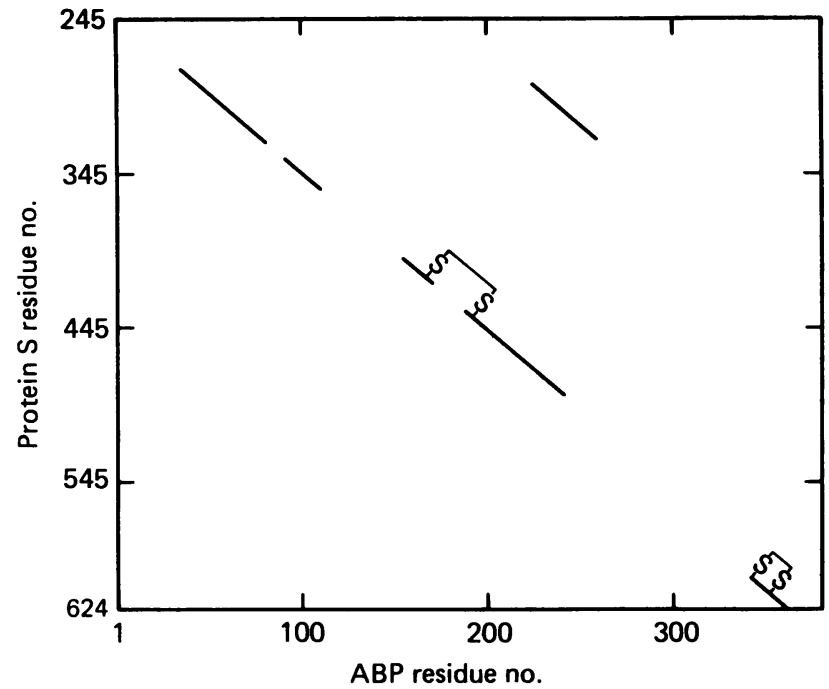

Fig. 1. Graphical representation of the similarity between bovine protein S and rat ABP (Maizel \& Lenk, 1981; Staden, 1982)

ABP and residues 245-624 of protein S were compared by using a 20-residue segment. Each pair of residues on these proteins was scored using the Mutation Data Matrix (Barker \& Dayhoff, 1982; Dayhoff et al., 1983). Segments with a score of 20 or larger are represented by a point at the midpoint of the segment. The segments along the diagonal are described in more detail in Fig. 2. Residues 282-315 of protein S appear to be similar to a second segment on ABP, residues 221-254. Disulphide bridges between residues 408 and 434, and 597 and 624 of protein $\mathrm{S}$ and residues 164 and 188, and 333 and 361 of ABP are shown as proposed by Dählback et al. (1986) and Walsh et al. (1986) respectively.

of biological needs (Doolittle, 1985; Patthy, 1985). All members of this family contain a vitamin K-modified domain, which is Gla-rich, at their $N$-terminus. This domain can bind $\mathrm{Ca}^{2+}$ tightly. In protein $\mathrm{S}$ this domain is important for its binding to phospholipid membrane surfaces, which is important in its cofactor activity with activated protein $C$. In protein S, Factors IX and X, and proteins $\mathbf{C}$ and $\mathrm{Z}$, this Gla-rich segment is followed by a domain that is called the 'growth-factor domain' because its amino acid sequence is similar to that of part of epidermal growth factor (Young et al., 1978; Doolittle et al., 1984; Doolittle, 1985; Patthy, 1985; Dahlbäck et al., 1986). An explicit function for this domain has not yet been established. In thrombin, another vitamin Kdependent protein, the Gla-rich domain is followed by two kringle structures, and there are no growth-factor domains. The last module of the vitamin K-dependent proteins, which comprises the rest of the $C$-terminal sequence, is a serine proteinase, or in the case of protein $\mathrm{Z}$, a non-catalytically active domain, that is clearly homologous with serine proteinases (Hojrup et al., 1985). The fact that protein $\mathbf{S}$ lacks this serine-proteinase-like module makes it unique among the vitamin K-dependent clotting factors.

The computer-based analysis presented here clearly show that this latter module of protein $\mathrm{S}$ is homologous with ABP (Figs. 1 and 2). The similarities in the sequences extend over most of ABP and residues 250-634 of protein S. Important for a possible functional similarity between these proteins is the apparent conservation of four cysteine residues and their disulphide linkages on protein S and ABP. Moreover, the gaps between the homologous segments are sufficiently similar in size to permit the segments to align in the tertiary structure of these proteins. Interestingly, segment A (Fig. 2), where the greatest conservation of the sequences of protein $\mathrm{S}$ and $\mathrm{ABP}$ occurs, is also the region where there is $90 \%$ homology between ABP and SBP (Joseph et al., 1986; Walsh et al., 1986), which suggests an important functional role for this segment in protein $\mathrm{S}, \mathrm{ABP}$ and SBP. All of the above suggests that this last module on protein $\mathrm{S}$ is likely to have some biological properties in common with ABP, which at first glance

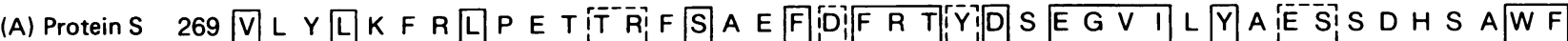

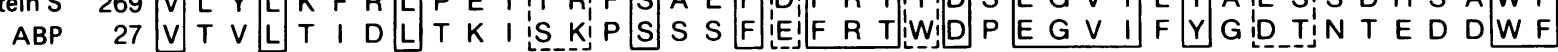

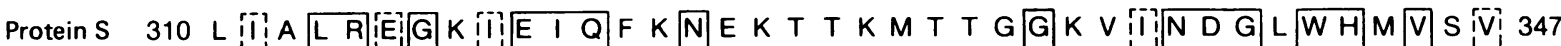
ABP 68 M L $\quad 6$ G

(B) Protein S 400 Piín N P R L D G C I R 410

ABP $\quad 156$ P L

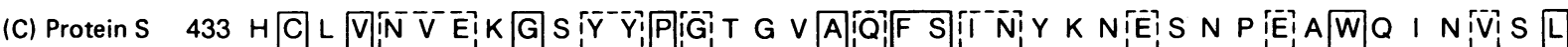
ABP $187 \mathrm{~N} C \mathrm{C}$ D V V D L Q

Protein S $472 \mathrm{~N}$ I R

ABP 226 G F L

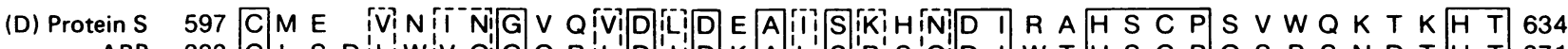
ABP 333 C L S D L L WIV_Q

Fig. 2. Comparison of bovine protein $S$ with Rat $\mathbf{A B P}$

Continuous-line boxes show identities and the broken-line boxes show conservative replacements according to the scheme: $(\mathrm{P}, \mathrm{G}),(\mathrm{M}, \mathrm{C}),(\mathrm{Y}, \mathrm{W}, \mathrm{F}, \mathrm{H}),(\mathrm{L}, \mathrm{V}, \mathrm{I}, \mathrm{A}),(\mathrm{K}, \mathrm{R}),(\mathrm{E}, \mathrm{Q}, \mathrm{N}, \mathrm{D})$ and $(\mathrm{S}, \mathrm{T})$. Cysteine-164, -188, -333 and -361 of ABP align with cysteine- $408,434,-597$ and -624 respectively of protein $S$. The one-letter amino acid notation is used. 
would be expected to be binding a hydrophobic ligand. Because protein $S$ has at least two protein-binding activities, which may involve residues $250-634$, the possibility that hydrophobic ligands have a role in regulating these actions of protein $S$ needs to be considered.

Even though ABP and SBP bind androgens and oestrogens with high affinity, the function(s) of this and their other properties (Hryb et al., 1985; Martin et al., 1986) are still obscure. The similarities between protein $\mathrm{S}$ and ABP and SBP suggest that, as the properties of residues $250-634$ of protein $S$ are deciphered, new activities for ABP and SBP may be revealed.

The computer analyses cannot resolve the question of the origin of residues $250-634$ of protein S. It is clear, however, that the first 250 residues of protein $S$ are related to those of the other clotting factors. The absence of a serine-proteinase domain on protein $S$ led Dahlbäck et al. (1986) to place protein $S$ on branch separate from a branch containing thrombin, a kringlecontaining clotting factor. The genealogy of the clotting factors is enriched by their similarity to members of the fibrinolytic factors, which contain growth-factor domains, kringles, and are serine proteinases (Young et al., 1978; Doolittle, 1985; Patthy, 1985). The shuffling of different functional modules among all of these proteins is one of the best examples of the variation of a few well-defined functions to achieve the diversity that is needed for the coagulation and fibrinolytic processes. Protein S, however, is unusual among these proteins in that the module that would be expected to be a serine proteinase is instead similar to a steroid-binding protein. We consider two possibilities for the origin of this module on protein S. First, it could be derived from a gene coding for a steroid-binding protein, which fused with the Gla-rich domain and growth-factor domain of a clotting-factor ancestor.

Second, it could be derived from the serine-proteinase ancestor that likely is common to the clotting and fibrinolytic factors. In this case, a combination of amino acid substitutions, frameshift mutations and gene duplications obscure the evidence in the primary amino acid sequence for its origin. The similarity between residues 282-315 of protein $S$ and two segments of ABP suggests that a gene duplication has occurred in these proteins, which could obscure their origin. Also relevant to this possibility is the extensive divergence in the primary amino acid sequences of the mammalian pancreatic and bacterial serine proteinases, which makes their sequence similarity marginal at best (James et al., 1978; Young et al., 1978; McLachlan, 1979; Doolittle, 1981), because a comparison of the tertiary structure of these enzymes, which is a more sensitive technique, clearly shows their common ancestry (James et al., 1978; McLachlan, 1979). The determination of the tertiary structure of protein S, ABP or SBP would more definitively resolve the ancestry of these proteins. Interestingly, there is some evidence for chemical similarities between steroid-hormone-binding proteins, including ABP and SBP, and proteinases. Serineproteinase inhibitors (e.g. di-isopropyl fluorophosphate or tosylphenylalanylchloromethane) and substrates (e.g. tryptophan methyl ester or tosylphenylalanine methyl ester) can inhibit the binding of steroids to SBP (M. E. Baker, unpublished work), rat $\alpha$-foetoprotein and intracellular receptors (Hunziker et al., 1980; Lukola \&
Punnonen, 1982; Baker, 1985, 1986; Baker et al., 1985; Hubbard \& Kalimi, 1985; Puca et al., 1986). One explanation for these findings is that the tertiary structure of steroid-binding proteins has some chemistry in common with proteinases (Baker, 1985, 1986; Baker et al., 1985).

Whatever the ancestry of protein $\mathrm{S}$ and $\mathrm{ABP}$, the similarities in their amino acid sequences suggests that, as each of these proteins becomes better understood, the resulting information could provide clues for understanding the functions of the other.

We thank Dr. P. Petra for communicating his results on SBP to us before their publication, and Dr. Darrell Fanestil and Dr. Lois Hunt for discussions. M.E.B. expresses his gratitude to Marvin F. Weissberg for encouragement and support. D.R.J. is supported by National Institutes of Health grant HD21744.

\section{REFERENCES}

Baker, M. E. (1985) FEBS Lett. 182, 47-52

Baker, M. E. (1986) Biochem. Int. 12, 331-340

Baker, M. E., Sklar, D. H., Terry, L. S. \& Hedges, M. R. (1985) Biochem. Int. 11, 233-238

Barker, W. C. \& Dayhoff, M. O. (1982) Proc. Natl. Acad. Sci. U.S.A. 79, 2836-2839

Comp, P. C., Nixon, R. R., Cooper, M. R. \& Esmon, C. T. (1984) J. Clin. Invest. 74, 2082-2088

Dahlbäck, B. (1983) Biochem. J. 209, 847-856

Dahlbäck, B. \& Stenflo, J. (1981) Proc. Natl. Acad. Sci. U.S.A. 78, 2512-2516

Dahlbäck, B., Lundwall, A. \& Stenflo, J. (1986) Proc. Natl. Acad. Sci. U.S.A. 83, 4199-4203

Dayhoff, M. O., Barker, W. C. \& Hunt, L. T. (1983) Methods Enzymol. 91, 524-545

DiScipio, R. G. \& Davie, E. W. (1979) Biochemistry 18, 899-904

Doolittle, R. F. (1981) Science 214, 149-159

Doolittle, R. F. (1985) Trends Biochem. Sci. 10, 233-237

Doolittle, R. F., Feng, D. F. \& Johnson, M. S. (1984) Nature (Lóndon) 307, 558-560

French, F. S. \& Ritzen, E. M. (1973) Endocrinology (Baltimore) 93, 88-95

Gardiner, J. E., McGann, M. A., Berridge, C. N., Fulcher, C. A., Zimmerman, T. S. \& Griffin, J. H. (1984) Circulation 70, suppl. 2, 820

Hansson, V., Reusch, E., Trygstad, O., Torgersen, D., Ritzen, E. M. \& French, F. S. (1973) Nature (London) 246, 56-58

Hansson, V., Calandra, R., Purvis, K., Ritzen, M. \& French, F. S. (1976) Vitam. Horm. (N.Y.) 34, 187-214

Hojrup, P., Jensen, M. S. \& Petersen, T. fE. (1985) FEBS Lett. 184, 333-338

Hryb, D. J., Kan, M. S. \& Rosner, W. (1985) Biochem. Biophys. Res. Commun. 128, 432-440

Hubbard, J. R. \& Kalimi, M. (1985) Mol. Cell. Biochem. 66, 101-109

Hunziker, W., Walters, M. R. \& Norman, A. W. (1980) J. Biol. Chem. 255, 9534-9537

James, M. N. G., Delbaere, L. T. J. \& Brayer, G. D. (1978) Can. J. Biochem. 56, 396-402

Joseph, D. R., Hall, S. H. \& French, F. S. (1986) Proc. Natl. Acad. Sci. U.S.A., 84, 339-343

Lukola, A. \& Punnonen, R. (1982) Biochem. Biophys. Res. Commun. 108, 822-827

Maizel, J. V. \& Lenk, R. P. (1981) Proc. Natl. Acad. Sci. U.S.A. 78, 7665-7669

Martin, M.-E., Vranckx, R., Benassayag, C. \& Nunez, E. A. (1986) J. Biol. Chem. 261, 2954-2959

McLachlan, A. D. (1979) J. Mol. Biol. 128, 49-79 
Patthy, L. (1985) Cell (Cambridge, Mass.) 41, 657-663

Puca, G. A., Abbondanza, C., Nigro, V., Armetta, I., Medici, N. \& Molinari, A. M. (1986) Proc. Natl. Acad. Sci. U.S.A. 83, 5367-5371

Schwarz, H. P., Fischer, M., Hopmeister, P., Batchard, M. A. \& Griffin, J. H. (1984) Blood 64, 1297-1300

Staden, R. (1982) Nucleic Acids Res. 10, 2951-2961

Received 11 November 1986/15 January 1987; accepted 4 February 1987
Walker, F. J. (1981) J. Biol. Chem. 256, 11128-11131

Walsh, K. A., Titani, K., Takio, K., Kumar, S., Hayes, R. \& Petra, P. H. (1986) Biochemistry 25, 7584-7590

Young, C. L., Barker, W. C., Tomaselli, C. M. \& Dayhoff, M. O. (1978) in Atlas of Protein Sequence and Structure (Dayhoff M. O., ed.), vol. 5, suppl. 3, pp. 73-93, National Biomedical Research Foundation, Washington, DC 